\title{
Soldagem a laser de aços de ultra-alta resistência
}

\section{Laser welding of ultra-high strength steel}

Andréia Souza Martins Cardoso ${ }^{1}$, Antonio Jorge Abdalla ${ }^{1}$, Felipe Martins Bonjorni', Milton Sérgio Fernandes Lima ${ }^{1}$,

Vladimir Henrique Baggio Scheid ${ }^{1}$, Leonardo Fanton², Carlos Antonio Reis Pereira Baptista ${ }^{3}$

\section{RESUMO}

Os aços alta resistência e baixa liga (ARBL), como o 4340 e 300M, e os aços de ultra alta resistência, Maraging, são tão importantes para o desenvolvimento industrial e de construção civil quanto para a defesa nacional. Os aços 4340 e 300M são utilizados no veículo lançador de satélites brasileiro (VLS), existem estudos para possibilitar a introdução e substituição dos aços ARBL pelos aços Maraging. Para a aplicação desse material na indústria automobilística, aérea e espacial, faz-se necessário o maior entendimento sobre a soldabilidade destes aços, correlacionando com suas propriedades mecânicas. Neste sentido, foram determinados através de trabalhos anteriores os parâmetros para uma soldagem a laser apropriada para estes três tipos de aço, com espessura de até $3 \mathrm{~mm}$, possibilitando uma análise comparativa das propriedades mecânicas e das características microestruturais dos mesmos. Nos aços 300M e 4340 ocorre têmpera com aumento de dureza na região soldada e um gradiente decrescente de dureza entre a zona fundida (ZF) e o material base (MB), para evitar a fragilidade é realizado um tratamento térmico de revenimento. No aço Maraging ocorre redução de dureza na zona fundida, um aumento de dureza em parte da zona termicamente afetada (ZTA) devido ao processo de precipitação e nova redução de dureza até atingir a dureza do substrato, em regiões mais afastadas da solda, para recuperar a resistência é realizado um tratamento de envelhecimento.

Palavras-chave:Soldaalaser; Aço ARBL; Açoultra-altaresistência; Tratamento térmico; Caracterização microestrutural; Propriedades mecânicas.

\begin{abstract}
The high strength steels low-alloy (HSLA) as the 4340 and 300M, and ultra-high strength steels as maraging steel are as important to the development of industrial and civil construction as for national defense. In Brazilian satellite launch vehicle (SLV) are used steels $300 \mathrm{M}$ and 4340 and there are studies to enable the introduction and replacement of HSLA steels for maraging steel. For the application of this material in the automotive, aviation and space industry, it is necessary a greater understanding of the weldability of these steels, correlating with its mechanical properties. In this regard, the parameters were determined by previous studies for welding suitable for these three types of steel with a thickness of up to $3 \mathrm{~mm}$, allowing a comparison of the mechanical properties and microstructural characteristics. In $300 \mathrm{M}$ and 4340 steels quenching occurs with increased hardness in the weld region and is observed a decreasing gradient of hardness between the fusion zone (FZ) and the base material (BM), to avoid brittleness is performed a heat treatment of tempering. In the Maraging steel the hardness reduction occurs in the fused zone, an increase in hardness in part of the heat affected zone (HAZ) caused by precipitation process and further reduction of hardness until the hardness of the substrate in regions farthest from the weld, to retrieve the resistance is carried out aging treatment.
\end{abstract}

Keywords: Laser welding; HSLA steel; Ultra-high steel; Heat treatment; Microstructural characterization; Mechanical properties.

${ }^{1}$ Instituto de Estudos Avançados - São José dos Campos (SP) - Brasil

${ }^{2}$ Faculdade de Engenharia de Guaratinguetá - Guaratinguetá (SP) - Brasil

${ }^{3}$ Escola de Engenharia de Lorena - Lorena (SP) - Brasil

Autor correspondente: Antonio Jorge Abdalla - Instituto de Estudos Avançados - Trevo Coronel Aviador José Alberto Albano do Amarante, 01, Putim CEP: 12228-001 - São José dos Campos (SP) Brasil

E-mail: abdalla@ieav.cta.br

Recebido: 03/10/2012 Aprovado: 27/02/2015 


\section{INTRODUÇÃO}

O Veículo Lançador de Satélites (VLS) e alguns veículos de sondagem que fazem parte do Programa Espacial Brasileiro são compostos por aços ARBL e de ultra-alta resistência. O aço 300M foi utilizado em substituição ao aço 4340 no VLS, devido aos excelentes resultados obtidos após a determinação dos parâmetros de tratamento térmico e de soldagem. O envelope metálico é responsável por suportar a pressão de trabalho durante a queima do propelente, cujo valor é de 60 bar. O envelope motor é basicamente um vaso de pressão feito a partir de chapas e fechamentos manufaturados de forjados e é soldado ${ }^{(1)}$.

Na década de 80, o Departamento de Ciência e Tecnologia Aeroespacial (DCTA) iniciou contatos para uma cooperação com as empresas Villares, Usiminas e Acesita, com o objetivo de elaborar um projeto de estudos do aço Maraging 300, visando sua aplicação em futuros VLS e de sondagem. O aço 300M está sendo gradualmente substituído com vantagens pelo aço da família Maraging. O DCTA está estudando a substituição do aço 300M pelo aço Maraging 300, que ainda não foi utilizado nos envelopes motores de foguetes $^{(2)}$.

A união por solda é extremamente importante na confecção do envelope motor, embora não se utilize ainda a solda a laser, compreender se há viabilidade e os mecanismos na solda deste aços é bastante relevante ${ }^{(3)}$.

Os aços 4340 foram escolhidos inicialmente por possuírem alta temperabilidade, alta resistência mecânica, elevada tenacidade, contudo usinabilidade e soldabilidade ruins. Têm baixa susceptibilidade à fragilização pelo hidrogênio, boa resistência à fadiga e são considerados de baixo custo e alta relação resistência/massa específica $^{(4)}$.

Devido as altas taxas de resfriamento na soldagem, boa parte da zona fundida e partes da zona afetada pelo calor transformam-se em martensita, recomenda-se um revenimento para reduzir o problema da fragilidade. Este processo aumenta a ductilidade, porém deve-se evitar o revenimento na temperatura de $300^{\circ} \mathrm{C}$, para este aço, pois pode ocorrer a formação de austenita retida e provocar fragilização ${ }^{(5,10,11)}$.

O aço SAE 4340 vem sofrendo desenvolvimento, e, pode se considerar o aço $300 \mathrm{M}$ como uma evolução deste aço. $\mathrm{O}$ aço $300 \mathrm{M}$ é basicamente um aço SAE 4340, modificado com a adição de teores de silício, próximos a 1,6\%, porém com concentrações de carbono e molibdênio ligeiramente maiores, além de conter vanádio. Este aço apresenta, como características principais, altaprofundidade de têmpera e mantém certa ductilidade e tenacidade a limites de resistência à tração de 1860 a $2070 \mathrm{MPa}$. Sua temperabilidade é melhor, conferindo ao material alta resistência mecânica em temperaturas mais elevadas $^{(3,6,11)}$.

Na década de 1960 foram desenvolvidos os aços Maraging, sendo ligas ferrosas de Ni-Co-Mo-Ti de ultra-alta resistência e vasta aplicação que vai desde a indústria bélica e nuclear até componentes aeronáuticos, vasos de pressão e a indústria esportiva, e por ser usado em áreas específicas, tornou-se um material controlado. Estes aços são martensíticos com baixíssimo teor de carbono, altamente ligados, em que a alta resistência mecânica é alcançada por envelhecimento e não pelo estado martensítico, como nos aços convencionais ${ }^{(9,11)}$. Nos aços Maraging ocorre uma reação metalúrgica que não envolve carbono, sendo o aumento das propriedades mecânicas obtido pela precipitação de compostos intermetálicos em temperatura na ordem de $480{ }^{\circ} \mathrm{C}$ com tempo de tratamento entre 3 e 6 horas. Ao contrário de muitos aços de alta resistência mecânica, os aços Maraging apresentam pouca distorção dimensional nos tratamentos térmicos, boa soldabilidade, boa combinação de resistência mecânica e tenacidade, o que facilita a sua utilização ${ }^{(7)}$. Este material com $18 \%$ de Ni, enquadrado na classe 300, têm sido proposto para substituir o aço $300 \mathrm{M}$ ou o aço 4340 em partes do VLS, assim como, nas aplicações na área de energias, automobilísticas e aeroespacial ${ }^{(8,11)}$.

Existem poucos estudos com relação ao processo de solda a laser do Maraging, embora exista interesse por parte da indústria aeronáutica e aeroespacial com relação ao material. Este trabalho propõe estudar este tipo de solda nestes três aços de uso aeroespacial, de modo a contribuir com o desenvolvimento tecnológico do setor.

\section{MATERIAIS E MÉTODOS}

Neste trabalho foram utilizadas chapas de aços SAE 4340, 300M e Maraging 300, com espessura de cerca de $3 \mathrm{~mm}$. A composição química está discriminada na Tabela 1.

As chapas foram cortadas em placas nas dimensões de $280 \mathrm{~mm}$ x $180 \mathrm{~mm}$ e retificadas em aproximadamente $3 \mathrm{~mm}$ de espessura. As placas dos aços 4340 e $300 \mathrm{M}$ foram submetidas, antes do processo de soldagem, ao tratamento térmico de recozimento a $950{ }^{\circ} \mathrm{C}$, durante 2 horas e resfriadas em forno com atmosfera controlada, até atingir a temperatura ambiente, tendo como objetivo eliminar os efeitos da laminação. O Aço Maraging 300, com espessura de $2,7 \mathrm{~mm}$, foi recebido solubilizado a $820^{\circ} \mathrm{C}$ por 1 hora e foi soldado nesta condição e na condição envelhecida a $480{ }^{\circ} \mathrm{C}$ por 3 horas.

O laser à fibra utilizado neste trabalho está instalado no Laboratório Multiusuário de Desenvolvimento e aplicações

Tabela 1: Composição química dos aços 4340, 300M e Maraging 300.

\begin{tabular}{cccccccccccccc} 
& $\mathbf{C}$ & $\mathbf{S i}$ & $\mathbf{M n}$ & $\mathbf{P}$ & $\mathbf{S}$ & $\mathbf{N i}$ & $\mathbf{C r}$ & $\mathbf{M o}$ & $\mathbf{C u}$ & $\mathbf{A l}$ & $\mathbf{T i}$ & $\mathbf{V}$ & $\mathbf{C o}$ \\
4340 & 0,39 & 0,3 & 0,69 & 0,016 & 0,007 & 1,8 & 0,81 & 0,22 & 0,12 & 0,023 & 0,0014 & 0,006 & - \\
300M & 0,43 & 1,83 & 0,83 & 0,008 & 0,007 & 1,69 & 0,78 & 0,39 & 0,13 & 0,035 & 0,0041 & 0,08 & - \\
Maraging 300 & 0,008 & 0,07 & 0,011 & 0,008 & 0,002 & 19,12 & 0,043 & 4,94 & 0,076 & 0,089 & 0,77 & - & 9,66 \\
\hline
\end{tabular}


de Lasers e Óptica (DedALO), do Instituto de Estudos Avançados (IEAv/DCTA). Trata-se de um laser de $2 \mathrm{~kW}$ de potência média (IPG, Modelo YLR-2000) dotado de uma fibra de saída com $50 \mu \mathrm{m}$ de diâmetro e 5 metros de extensão.

Foram utilizadas soldas por penetração autógenas, tipo bead-on-plate. Os parâmetros do processo (potência do laser e velocidade do passe) foram estudados de forma a obter uma solda estreita e com a profundidade desejada, na região soldada foi utilizado o gás argônio com fluxo de 30 l/min e para proteger a cabeça do dispositivo foi usado o gás nitrogênio. $\mathrm{O}$ foco foi mantido na superfície das chapas com inclinação da cabeça de $5^{\circ}$ e distância focal de 160,5 mm com a lente em $160 \mathrm{~mm}$.

Visando reduzir as tensões pós-soldagem, nos aços 4340 e $300 \mathrm{M}$, foi realizado um tratamento térmico de revenimento a $400{ }^{\circ} \mathrm{C}$ por 2 horas em ambos os aços, potencializando a difusão e queda de tensões nas regiões com solidificação rápida e segregação, sendo assim, para esses aços os lotes estudados foram: recozido e soldado (RS) e recozido, soldado e revenido (RSR). Para o aço Maraging, foram estudadas duas condições, sendo elas, solubilizado e soldado (SS) e solubilizado, soldado e envelhecido (SSE). O primeiro lote (SS) foi solubilizado a $820^{\circ} \mathrm{C}$, posteriormente soldado a laser, mostrando formação de diferentes ZTA's, e regiões com diferentes concentrações de austenita, assim como, queda de dureza no cordão de solda (CS), sem presença de precipitados decorrentes da ausência tratamento específico da liga. O segundo lote (SSE) foi solubilizado, soldado e envelhecimento a $480^{\circ} \mathrm{C}$ por 3 horas, para melhoria das propriedades mecânicas nas regiões formadas entre a ZF, ZTA's e MB, possibilitando a formação de precipitados que é característico da liga aqui estudada e minimizando queda de dureza no cordão de solda (CS).

Para a realização das análises microestruturais foram retiradas amostras dos materiais nas seguintes condições: conforme recebido, após soldagem a laser, após soldagem e tratamentos térmicos de revenimento ou de envelhecimento. Os cordões de solda foram analisados no sentido transversal. Foram caracterizadas as zonas fundidas (ZF), zonas termicamente afetadas (ZTA) e metal base $(\mathrm{MB})$. As amostras foram preparadas metalograficamente e foram submetidas aos ataques químicos com: nital $2 \%$, solução aquosa de metabissulfito de sódio $10 \%$ e reagente fry. As análises microscópicas foram realizadas via microscopia óptica (MO) e microscopia eletrônica de varredura (MEV). As análises da fração volumétrica de austenita retida foram realizadas com a utilização do software Image J. Foram realizadas medidas de dureza por microindentação em um equipamento Future Tech modelo FM-700, com carga de 50 gf. Os corpos de prova e os ensaios de tração foram realizados de acordo com a norma ASTM E8M-04 à temperatura ambiente. O equipamento utilizado foi uma máquina servo-hidráulica MTS $810.23 \mathrm{M}$, com célula de carga com capacidade de $250 \mathrm{kN}$. A velocidade do deslocamento do atuador foi de $1 \mathrm{~mm} / \mathrm{min}$. Foram ensaiados 3 corpos de prova para cada condição de tratamento e tipo de aço.

\section{RESULTADOS}

Após estudos anteriores os parâmetros de laser que melhor responderam ao processo de soldagem, para a espessura desejada foram: potência de $1400 \mathrm{~W}$ para o aço $300 \mathrm{M}$ e $1600 \mathrm{~W}$ para o aço 4340, com velocidade de soldagem de $50 \mathrm{~mm} / \mathrm{s}$. Para o aço Maraging 300 os melhores parâmetros de potência foram 1600W para o aço envelhecido e $1800 \mathrm{~W}$ para o aço não envelhecido e velocidade de soldagem de $20 \mathrm{~mm} / \mathrm{s}^{(3,9)}$. As micrografias mostradas nas Figs. 1A e 1B mostram o aspecto geral da região soldada para os aços 4340 e $300 \mathrm{M}$ respectivamente, feitas por microscopia óptica após ataque com nital. A micrografia da Fig. 2 mostra estas mesmas características para o aço Maraging 300, atacado com o reagente fry. A profundidade atingida entre o topo e a raiz da solda foi de 2,5 a $3 \mathrm{~mm}$, o topo da solda tem entre $0,8 \mathrm{e}$ $1,3 \mathrm{~mm}$ e mais próximo a raiz estreita para uma espessura entre $0,4 \mathrm{a}$ 0,5 mm, conforme mostrado nas Figs. 1 e 2. É possível atingir profundidades maiores no cordão aumentado-se a potência, reduzindo a velocidade do laser, usando hélio ou mudando o foco.

A

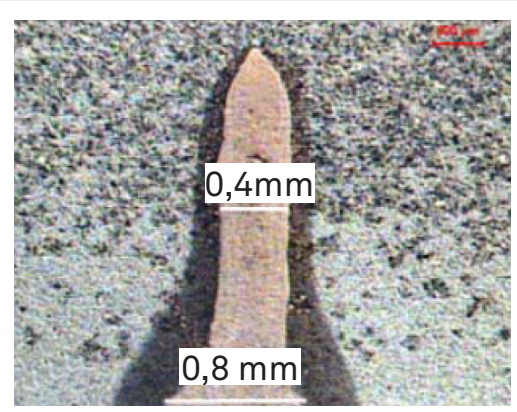

B

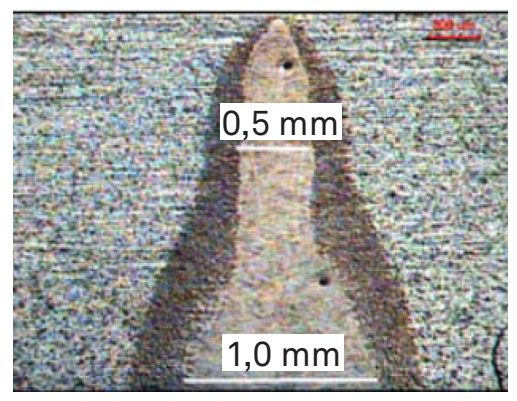

Figura 1: Região soldada e zona termicamente afetada dos aços $4340(\mathrm{~A})$ e $300 \mathrm{M}(\mathrm{B})$.

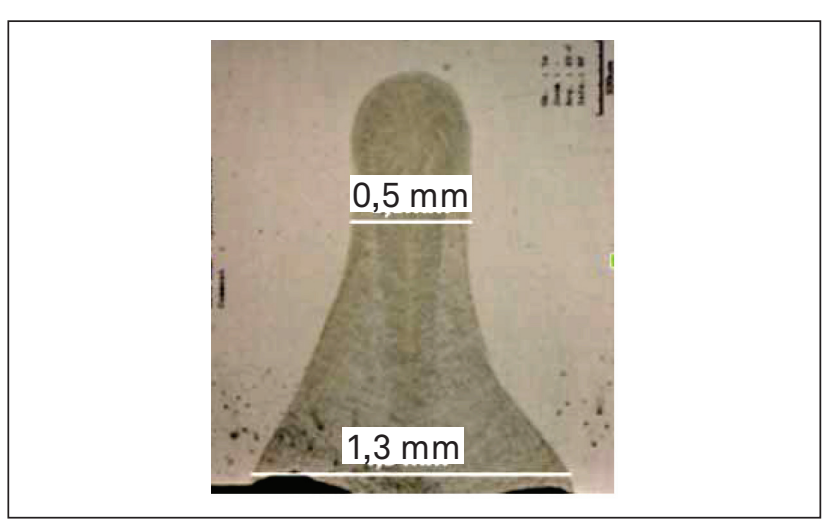

Figura 2: Região soldada do aço Maraging 300. 
Devido ao rápido aquecimento e resfriamento no processo de soldagem ocorrerá a formação de uma zona termicamente afetada (ZTA) entre a zona fundida (ZF) e o material base (MB). A seguir são mostradas micrografias das Figs. 3 e 4 detalhes de cada uma destas regiões, com espessuras próximas para todos os aços estudados. Há uma semelhança entre as composições químicas dos aços 4340 e $300 \mathrm{M}$ e, devido principalmente o teor de
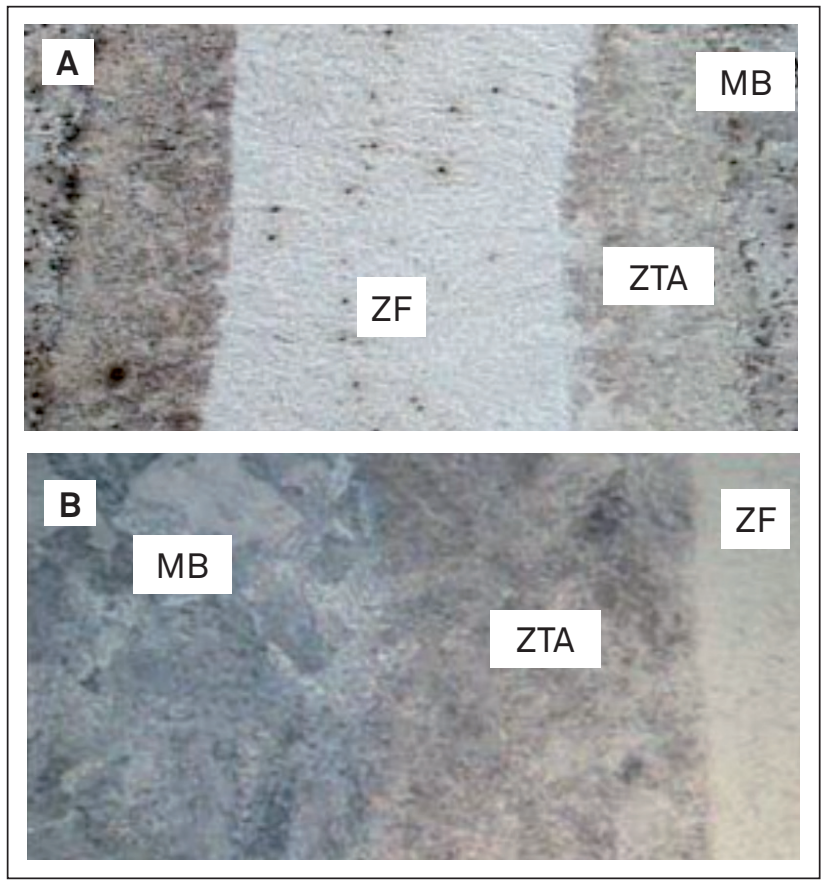

Figura 3: $\mathrm{MO}$ mostrando a região soldada e zona termicamente afetada dos aços: (A) 4340 e (B) 300M após ataque Nital 1,5\%.

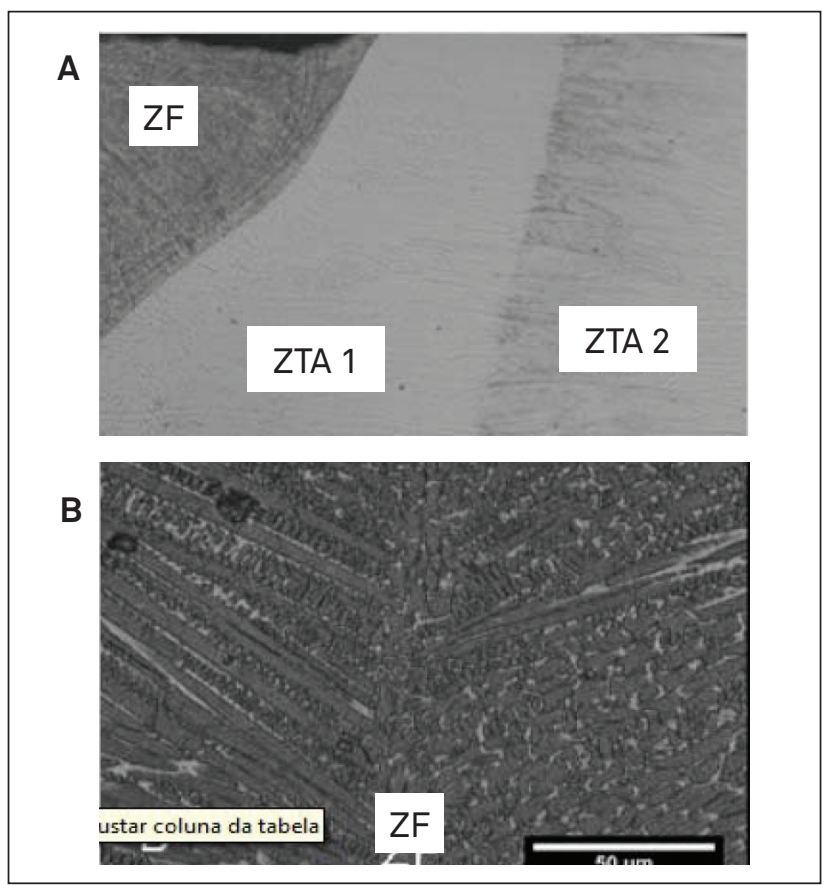

Figura 4: MEV do aço Maraging 300 (SS): (A) Zona Fundida e Zonas Afetadas pelo Calor (ZTA) - Nital 5\%; (B) Detalhe da Zona Fundida - Metabissulfito de sódio. carbono e o rápido resfriamento da região fundida há a formação de martensita, nas proximidades da poça de solda (ZTA) ocorre transformação de fase com possível formação de bainita, martensita e, ainda na ZTA, pequeno crescimento de grão. Nota-se, comparando as Figs. 3A e 3B que a zona afetada pelo calor do aço $300 \mathrm{M}$ é um pouco maior que a do aço 4340 , devido a sua melhor temperabilidade.

No aço Maraging, que tem natureza martensítica, apresenta regiões distintas sendo elas, a ZF, ZTA 1 e ZTA 2, conforme apresentada na Fig. 4 A. A ZTA 1 sofrerá envelhecimento e com isso, precipitação de intermetálicos, devido a alta temperatura atingida localmente com resfriamento rápido, efeito oriundo da transferência de calor proveniente da ZF. Na ZTA 2 a intensidade térmica será menor favorecendo um envelhecimento parcial e crescimento de grão.

Na Fig. 4.B, referente à zona fundida no aço Maraging, além da formação de dendritas, observa-se a formação de austenita, reconhecidas nas regiões arredondadas e mais claras da imagem, essa fase CFC segue a mesma estrutura por ter estrutura semelhante à cúbica presente na formação da martensita, favorecendo numa menor tensão residual (proveniente da menor expansão do reticulado) e apresentando características mais dúcteis, conferindo ao aço Maraging tenacidade após tratamento de envelhecimento, favorecendo na queda da fragilidade do mesmo. Após o processo de soldagem dos aços 4340 e 300M foi realizado um tratamento térmico de revenimento para evitar a fragilidade típica da fase martensita, formada na zona fundida e na zona termicamente afetada pelo calor. Os gráficos das Figs. 5 e 6 mostram a redução de dureza na zona fundida após o tratamento térmico proposto. Para o aço 4340 há uma diminuição na dureza de cerca de $600 \mathrm{HV}$ para a faixa de $450 \mathrm{HV}$. De forma semelhante, para o aço $300 \mathrm{M}$ a martensita da zona fundida atinge em torno de $700 \mathrm{HV}$ e, após o revenido, esta dureza se aproxima de $500 \mathrm{HV}$.

Para o aço Maraging, ocorre o processo inverso, a martensita formada na zona de fusão tem baixa dureza, conforme pode ser visto no gráfico da Fig. 7 e, após o envelhecimento, ocorre um aumento da dureza na região soldada e também no material base, devido a formação de precipitados

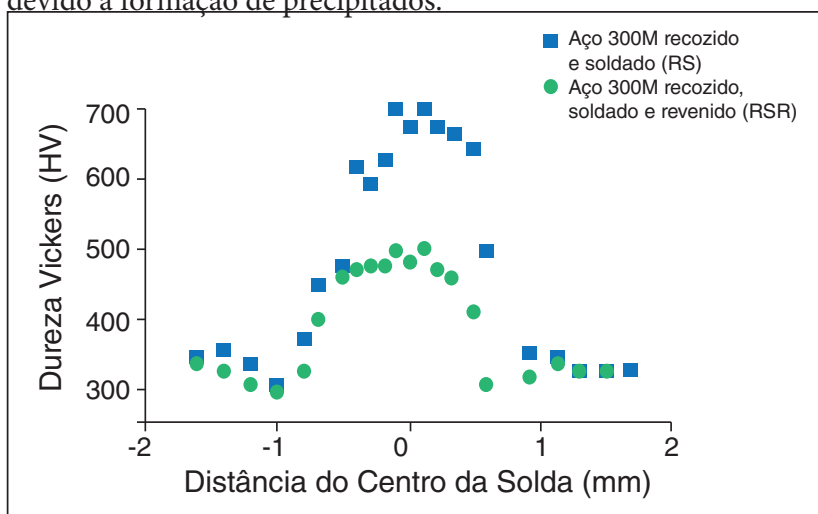

Figura 5: Dureza obtida por microindentação na região da solda do aço 4340 (antes e após revenimento). 


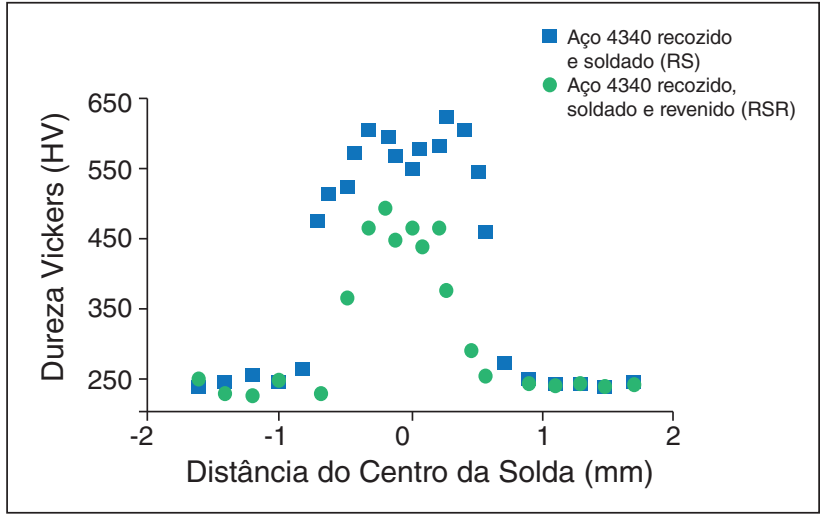

Figura 6: Dureza obtida por microindentação na região da solda do aço $300 \mathrm{M}$ (antes e após revenimento).

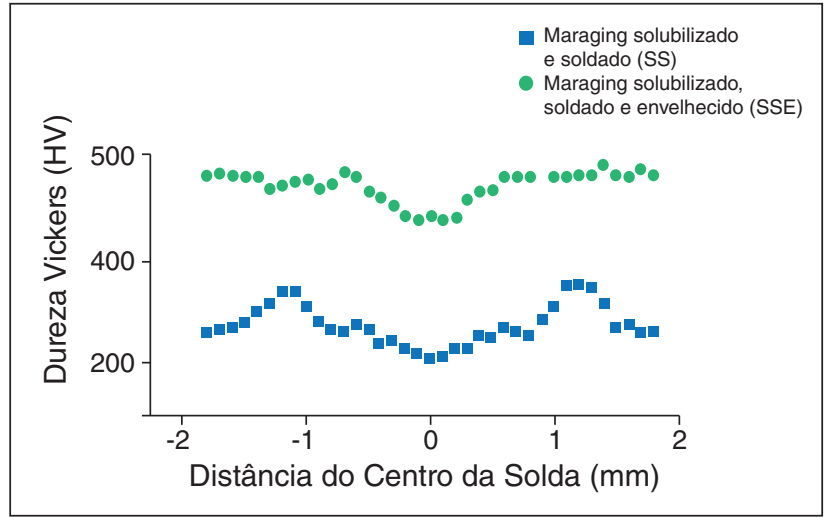

Figura 7: Microdureza obtida por microindentação na região da solda do aço Maraging 300 (antes e após o envelhecimento).

Tabela 2: Resultados comparativos das propriedades dos aços 4340, 300M e Maraging 300 em diferentes condições de tratamentos térmicos.

\begin{tabular}{|c|c|c|c|c|c|}
\hline Material & $\begin{array}{c}\text { Dureza MB } \\
(\mathbf{H V})\end{array}$ & $\begin{array}{c}\text { Dureza ZF } \\
(\mathbf{H V})\end{array}$ & $\begin{array}{c}\sigma_{\mathbf{t}}(\mathbf{M P a}) \\
\Delta \mathbf{L}_{\mathbf{0}}\end{array}$ & $\begin{array}{c}\text { Austenita (\%) } \\
\text { ZF/ZTA }\end{array}$ \\
\hline $4340(\mathrm{RS})$ & 250 & 580 & 718 & 21 & 4 \\
\hline $4340(\mathrm{RSR})$ & 210 & 450 & 736 & 22 & 4 \\
\hline 300M (RS) & 320 & 650 & 974 & 8,4 & 6 \\
\hline 300M (RSR) & 300 & 500 & 972 & 12 & 5,5 \\
\hline Maraging 300 (SS) & 380 & 300 & 900 & 7,1 & 1 \\
\hline Maraging 300 (SSE) & 500 & 450 & 1890 & 5,8 & 10 \\
\hline
\end{tabular}

Nos processos de tratamentos aplicados, nos três aços estudados, há uma aproximação entre os valores de dureza do material base, da zona fundida e da zona termicamente afetada, indicando que os tratamentos realizados após a solda são benéficos para trazer maior homogeneidade à microestrutura dos aços soldados a laser, elevando assim, as propriedades dos materiais. A Tabela 2 apresenta os resultados de propriedades mecânicas e austenita retida/reversa dos aços estudados.

Os aços 4340 e $300 \mathrm{M}$ apresentaram queda de dureza da condição RS para a RSR, proveniente do aquecimento que possibilitou a difusão e alívio de tensão do material após revenimento, contudo a tensão máxima apresentada, após ensaio uniaxial em triplicata, mostrou pequena melhora para SR em ambos os aços, com melhoras no alongamento. Os aços Maraging 300 ultra-alta resistência, na condição SS, apresentou resultados semelhantes aos aços 4340 e 300M, contudo após tratamento de envelhecimento, ocorreu uma duplicação da tensão máxima com pequena queda no alongamento, mostrando que esse material tem potencial para substituir os aços 4340 e 300M (ARBL) em suas aplicações, com tendência a melhoria na resposta mecânica. Importante observar que a presença do cordão de solda e zona termicamente afetada não afetaram as propriedades dos materiais em ensaios uniaxiais.

\section{CONCLUSÕES}

As análises microestruturais mostraram a viabilidade do processo de solda a laser de aços ARBL e ultra-alta resistência, os parâmetros utilizados foram eficazes para a união de chapas de $2 \mathrm{~mm}$ a $3 \mathrm{~mm}$ de espessura.
A solda dos aços 4340 e $300 \mathrm{M}$ mostrou que, devido ao rápido resfriamento ocasionado pelo processo a laser, há a formação de martensita na estrutura dendrítica da zona fundida e em parte da zona afetada pelo calor. O tratamento térmico de revenido reduz a dureza destas zonas, contribuindo para melhorar a sinergia entre esta região e o material base.

Os parâmetros escolhidos para a solda do aço Maraging mostraram-se também satisfatórios para realizar a solda conforme proposto, ocorrendo uma redução de dureza na zona fundida. O tratamento posterior de envelhecimento mostrou-se útil e necessário para recuperar e elevar os valores de dureza da região soldada e também do material base.

$\mathrm{Na}$ análise comparativa das propriedades mecânicas, junto a fração de austenita, observou-se que após tratamento de envelhecimento, o aço Maraging 300 possui resultados superiores aos aços ARBL, mostrando potencial para substituição.

\section{AGRADECIMENTOS}

Os autores agradecem à CAPES, Projeto Pró-Defesa 014/08 e ao Instituto de Estudos Avançados (IEAv/DCTA).

\section{REFERÊNCIAS}

1. BOSCOV, J. Foguetes de Sondagem. Brasília: Agência Espacia Brasileira, $1^{\circ}$ Curso de Tecnologia Espacial, 1996

2. BOSCOV, J. Veículos Lançadores de Satélites. Brasília: Agência Espacial Brasileira, $1^{\circ}$ Curso de Tecnologia Espacial, 1996. 
3. CARDOSO, A.S.M; BAPTISTA, C.A.R.P.; CARVALHO, S.M.; ABDALLA, A.J.; LIMA, M.S.F. Estudo do comportamento da soldabilidade a laser dos aços de alta resistência e baixa liga AISI 4340 e $300 \mathrm{M}, 19^{\circ}$ Congresso Brasileiro de Engenharia e Ciência dos Materiais - CBECiMat, 2010.

4. SOUZA, R. C., Estudo do comportamento em fadiga do aço ABNT 4340 revestido com carbeto de tungstênio pelo sistema HVOF/HP. 1998, 158f. Dissertação de Mestrado (1998) Faculdade de Engenharia de Guaratinguetá, FEG/UNESP, Guaratinguetá.

5. LEE, W. S.; SU, T.-T. Journal of Materials Processing Technology, vol. 87 (1997) p. $198-206$.

6. PHILIP, T. V. Ultrahigh-Strength Steels. Metals Handbook - ASM, vol. 1, Properties and selection: Iron and Steels, 9 ed. (1978) 6.

7. HALL, A.M. , The Metall. behavior and application of the $18 \mathrm{Ni}$ Maraging Steel, Relatório NASA, 1968.
8. NETO, C.M.; ALMEIDA, D.S. Materiais para fabricação de vasos de pressão de alto desempenho. In: Congresso Internacional de Tecnologia Metalúrgica de Materiais, $2^{a}$ Ed. ABM, São Paulo, 1997.

9. FANTON, L. ; ABDALLA, A. J. ; LIMA, M. S. F. Heat Treatment and Yb- Fiber Laser Welding of a Maraging Steel. Welding Journal, v. 93, p. 362-368, 2014.

10. CARDOSO, A. S. M., ABDALLA, A. J., BAPTISTA, C. A. R.P., LIMA, M.S.F.; Comparison of High Cycle Fatigue in 4340 and 300M Steel Welded with Fiber Laser, Advanced Materials Research, Vols. 891-892 (2014) pp 1507-1512.

11. CARDOSO A.S.M., ABDALLA A. J., LIMA M. S. F.; Comparative study of laser welding and heat treatments done in three types of high strength steel: 4340, 300M, Maraging 300; SAE International, 2013. 